\title{
Low power current sources for bioimpedance measurements: a comparison between Howland and OTA-based CMOS circuits
}

\author{
Pedro Bertemes-Filho ${ }^{1,2}$, Volney C. Vincence ${ }^{1}$, Marcio M. Santos ${ }^{1}$ and Ilson X. Zanatta ${ }^{1}$ \\ 1. Department of Electrical Engineering, State University of Santa Catarina, Joinville, Brazil \\ 2. E-mail any correspondence to: bertemes@joinville.udesc.br
}

\begin{abstract}
Multifrequency Electrical Bioimpedance (MEB) has been widely used as a non-invasive technique for characterizing tissues. Most MEB systems use wideband current sources for injecting current and instrumentation amplifiers for measuring the resultant potential difference. To be viable current sources should have intrinsically high output impedance for a very wide frequency range. Most contemporary current sources in MEB systems are based on the Howland circuit. The objective of this work is to compare the Mirrored Modified Howland Current Source (MMHCS) with three Operational Transconductance Amplifier (OTA) based voltage controlled current sources (i.e., class-A, class- $\mathrm{AB}$ and current conveyor). The results show that both current conveyor and class-AB OTA-based current sources have a wider output current frequency response and an output impedance of $226 \%$ larger than the MMHCS circuit at $1 \mathrm{MHz}$. The presented class-AB OTA circuit has a power consumption of $4.6 \mathrm{~mW}$ whereas current conveyor consumed $1.6 \mathrm{~mW}$. However, the MMHCS circuit had a maximum total harmonic distortion of $0.5 \%$ over the input voltage from -0.5 to $+0.5 \mathrm{~V}$. The OTA-based current sources are going to be integrated in a semiconductor process. The results might be useful for cell impedance measurements and for very low power bioimpedance applications.
\end{abstract}

Keywords: Howland circuit, OTA, current conveyor, bioimpedance

\section{Introduction}

Multifrequency electrical bioimpedance, also called Electrical Impedance Spectroscopy (EIS), has been widely used as a non-invasive technique for measuring many passive electrical properties from biological materials, such as: cancerous tissues (1-4); tumors $(5,6)$, meningitis $(7)$ and brain cellular oedema $(8,9)$. It can also be used for analyzing body composition $(10,11)$ and bovine milk quality $(12,13)$. Also, it is considered fast, inexpensive, practical, and efficient $(14,15)$. Its availability for emerging wearable applications (16) and for on-chip systems such as the $\operatorname{AD5933}(17,18)$ have also made its popularity grow. Microelectronics systems applied to health care solutions provide the advantages of small size devices, possible wireless signal and power transmission, portability, long time implant for low power circuits, and the possibility of improving the sensing of weak signals (on the order of milivolts) by taking them out in-situ (19-21).

EIS techniques have shown good results for detecting normal and cancerous skin in superficial tissues (22-26). Most EIS systems consist of applying a multi-frequency sinusoidal current of constant amplitude into the tissue sample, measuring the resulting potential, and then calculating the transfer impedance $\left(Z_{t}\right)(14,15)$. In order to get accurate calculated transfer impedances, it is necessary to ensure that the injecting current has a constant amplitude over a wide frequency range, which may be obtained by using a current source with high output impedance $(14,15)$. However, stray capacitances are known reduce the current amplitude at higher frequencies $(27,28)$. High performance current sources with wide bandwidths based on operational amplifiers have been widely developed and can be found throughout the literature (29-31) while others have used integration techniques for developing current sources (3237). An integrated realization of a Voltage-Controlled Current Source (VCCS) for bioimpedance applications $(33,38,39)$, which are based on the operational transconductance amplifier (OTA) approach. Our targeted measuring applications require an operating frequency band of $1 \mathrm{kHz}$ to $1 \mathrm{MHz}$ and current amplitudes of up to $500 \mu \mathrm{A}_{\mathrm{p}}$ (peak).

A VCCS for EIS may be analog or mixed-signal. In addition, it can be single-ended or differential and the system may include a single or multiple current sources (34). Single-ended systems always have large commonmode voltages since one end is tied to virtual ground (35). Although transformer coupling can reduce this effect (35), the use of a transformer is not suitable for an integrated solution. Reducing the common-mode voltage without decreasing the output impedance of the source is required. Because the digital noise appears in terms of a common mode voltage, fully differential structures are highly recommended for low-power systems as they are intrinsically immune from common mode signals. The fully differential amplifiers have the advantage of having twice the output voltage swing compared to the single-ended ones (40). Furthermore, increasing the amplifier dynamic range is significantly important for low power applications as it also reduces the even harmonic distortion of the output signal. Therefore, the use of differential current sources allows the minimization of the common mode voltage at the load, and then reducing the errors due to limited commonmode rejection ratio of the voltage measuring amplifiers (41).

The main objective of this paper is to compare the performance of the Howland circuit based on active and passive elements with circuit topologies at a transistor level. Three OTA-based CMOS (i.e., class-A, class-AB and 
current conveyor) VCCSs for wideband EIS instrumentation are described in the paper and are compared at a simulation level to the Mirrored Modified Howland Current Source (MMHCS) circuit. The OTAbased circuits were designed in a $0.35 \mu \mathrm{m}$ CMOS technology and simulation results are presented.

\section{Materials and methods}

Three types of OTA-based CMOS circuits were made: class- $\mathrm{A}$, class- $\mathrm{AB}$ and current conveyor. The performances of these circuits were compared with the MMHCS circuit in order to obtain linearity, total harmonic distortion, output current, and impedance response in the frequency range from $10 \mathrm{~Hz}$ to $1 \mathrm{GHz}$. Comparisons were done by using PSPICE simulator from Orcad (2009 version). The basic OTA-based circuits were modified using linearization techniques and current mirrors at the output stages to improve the output impedance.

\section{Mirrored Modified Howland Current Source (MMHCS)}

An MMHCS circuit was implemented using two wide bandwidth operational amplifiers OPA657 (Burr Brown, Inc.), as shown in Figure 1. The OPA657 has an open-loop gain of $70 \mathrm{~dB}$, a bandwidth of $10 \mathrm{MHz}$ for voltage gain of $160 \mathrm{~V} / \mathrm{V}$ with $1.6 \mathrm{GHz}$ for unit gain, a power supply of \pm 5 $\mathrm{V}$, and a bias current of $16 \mathrm{~mA}$. The MMHCS is a voltage controlled current source with a floating load $R_{L}$ and consists of two symmetrical modified Howland structures $(28,29)$. It is set to supply an output current $\mathrm{I}_{\mathrm{O}}$ of $1 \mathrm{mApp}$ (peak to peak) over the frequency range $10 \mathrm{~Hz}$ to $1 \mathrm{GHz}$, which is ideally controlled by the ratio between the input voltage $\mathrm{V}_{\text {in }}\left(=1 \mathrm{~V}_{\mathrm{pp}}\right)$ and the resistor " $\mathrm{r}$ " $(=1 \mathrm{k} \Omega)$.

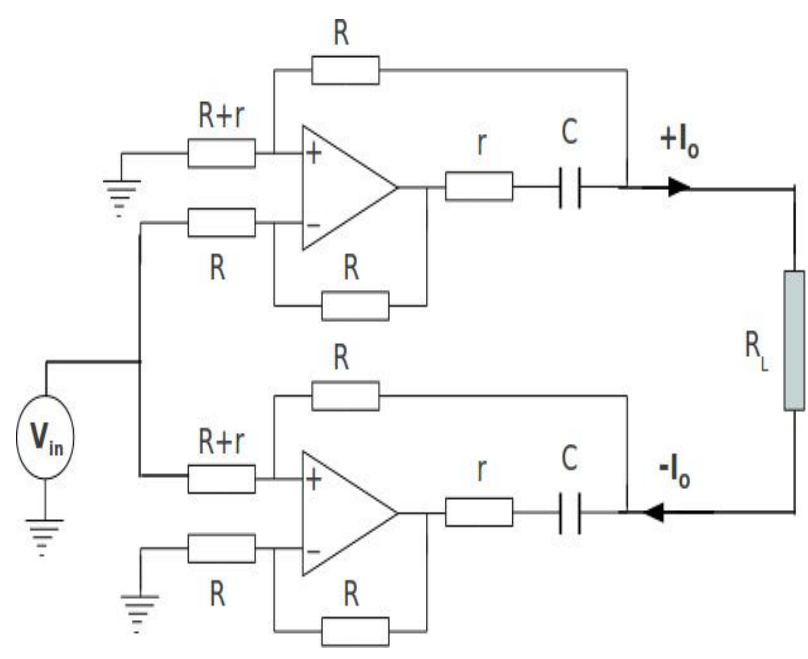

Fig.1: Schematic diagram of the simulated mirrored modified Howland current source, where $\mathrm{R}=47 \mathrm{k} \Omega, \mathrm{C}=2 \mu \mathrm{F}$ and $\mathrm{V}_{\text {in }}$ is the input signal.

The differential output impedance of this structure depends on the open-loop gain A, which is frequency dependent, as shown in Equation 1. The input impedance of the operational amplifier was not taken into account.

$$
Z_{\text {out }}=\frac{(2 \cdot R+z) \cdot\left[(2 \mathrm{R}+z) \cdot Z_{0}+z \cdot R \cdot(A+2)\right]}{Z_{0} \cdot(2 \cdot R+z)+2 \cdot R \cdot(R+z)}
$$

where $\mathrm{z}$ is the series impedance of the resistor $\mathrm{r}$ with capacitance $\mathrm{C}, \mathrm{Z}_{0}$ is the output impedance of the operational amplifier, and $\mathrm{R}$ is the resistor of the current source (see Figure 1) in order to make a mirrored structure by considering ideal operational amplifiers.

The circuit linearity ( $\mathrm{I}_{\mathrm{O}}$ versus $\mathrm{V}_{\text {in }}$ ) was investigated by DC sweeping the input voltage signal $V_{\text {in }}$ from -0.6 to +0.6 volts with the frequency response of the output current measured directly across a $1 \mathrm{k} \Omega$ load.

\section{Class-A OTA}

This is an Operational Transconductance Amplifier (OTA) implemented to operate as a class-A amplifier. It uses a semiconductor based on a CMOS structural width down to $0.35 \mu \mathrm{m}$, which is manufactured by Austria Microsystems. The circuit was implemented to have a common mode control through the transistors M6 and M7 operating in the triode region (see Figure 2). It has a modified cascode output structure using the transistors M12 and M13 to increase output impedance. The source degeneration is done by using the MOS transistors MA and MB operating in the triode region. The class-A OTA circuit was projected to have a transconductance of $1 \mathrm{mS}$ (see Equation 2) and an output current of $1 \mathrm{~mA}_{\mathrm{pp}}$ (peak to peak) over the frequency range from $1 \mathrm{~Hz}$ to $1 \mathrm{MHz}$. The circuit is supplied by a voltage source of $\pm 1.5 \mathrm{~V}$ ( $\mathrm{VSS}=$-VDD), where $\mathrm{Ib}$ is a external bias current set to $500 \mu \mathrm{A}, \mathrm{V} 1,2$ are voltage input signals, Vcas1,2 and Vbias are DC voltages of the cascode pairs and Vout + and Vout- can be considered as a fullydifferential output, where the load is connected between these nodes.

$$
G_{m}=\frac{g_{d s}}{1+\frac{2 \cdot g_{d s}}{g_{m 1}}}
$$

where $g_{m l}$ is the transconductance of transistor M1, $g_{d s}$ is the conductance of transistor MA. The output resistance of each output nodes (Vout+ and Vout-) of the class-A OTA is approximately equal to the product of $\mathrm{g}_{\mathrm{m} 9}, r_{o g}$ and $r_{o l l}$, where $r_{o l l}$ is the output resistance of transistor M11 and $r_{o 9}$ and $g_{m} 9$ are the output resistance and conductance of the transistor M9, respectively.

\section{Class-AB OTA}

This is an OTA implemented to operate as a class- $\mathrm{AB}$ amplifier. It uses the same technology as class-A OTA 
described in the previous section. Basically, it contains a main functional structure (see M1, M2, M5, Ma and Mcas transistors in Figure 3), which is a modified structure proposed by Carvajal (43) called a flipped voltage follower. It is used in low-voltage and low-power cells to work as a class-AB circuit, where the Ma transistor (see Figure 3 ) is polarized by the constant current source $\mathrm{Ib}$ so that the voltage applied in the gate of this transistor is copied to its source as a positive displacement voltage Vgs. The transistors M1 and M2 are connected in low impedance nodes, which are supplied by drains of the transistors M5 and M6, respectively. The voltages $\mathrm{Va}$ and $\mathrm{Vb}$ are projected so that the differential transistor pairs M1,2 and M3,4 work as a fully differential class-AB voltage input. The output stage formed by the transistors M7, M9, M11, M13, M15, M17, M19, M21, M23 and M25 makes the subtraction of the currents "I2+I4" (I2 is the current through transistor $\mathrm{M} 2$, for example) and "I1+I3". From the other output stage, at Vout + , the output current is given by Equation 3.

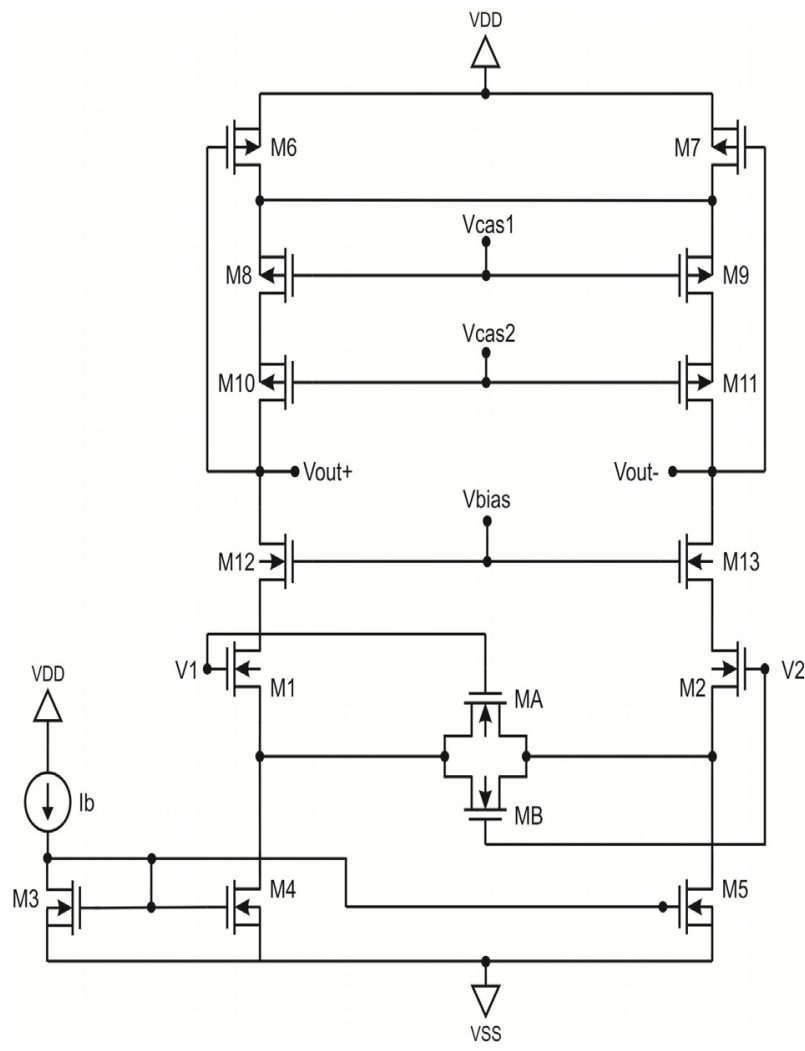

Fig.2: Schematic diagram of the simulated CMOS class-A operational transconductance amplifier (modified from (42)).

$$
I_{0}=\left(I_{1}+I_{3}\right)-\left(I_{2}+I_{4}\right)=2 \mathrm{~K} \cdot\left(V_{1}-V_{2}\right) \cdot(\mathrm{Va}-\mathrm{Vb})
$$

where $\mathrm{K}$ is the transistor gain factor of M1-M4.

For this type of CMOS OTA current source, the transconductance is given by Equation 4. As a result, the total output current that flows through the load is fully differential and the load is floating.

$$
G_{m}=\frac{I_{0}}{V_{1}-V_{2}}=2 \mathrm{~K} \cdot(\mathrm{Va}-\mathrm{Vb})
$$

\section{Current Conveyor}

The Current Conveyor Current Source (CCCS) can be implemented by using translinear structures (44-46) or differential pairs $(47,48)$. Figure 4 shows a current conveyor circuit based on two differential pairs of transistors M1-M2 and M3-M4, which allows a rail-to-rail input stage (49). This type of current source is called current conveyor second generation (CCII) due to the its input and output characteristics (39). The transistors M13 and M14 are source followers used to keep a low resistance in the $\mathrm{X}$ terminal and to stabilize the bias current through the transistors M8 and M12. The transconductance of the current conveyor current source is given by Equation 5, considering the transistors M1, M2, M3 and M4 from the differential pairs well matched, where $g_{m 1}=g_{m 2}=g_{m 3}=g_{m 4}=g_{m d i f}$. Also, the load transistors M5, M6, M9 and M10 are considered to have equal output resistances $r_{0}$ and the conductance of the transistors M13 and M14 are also matched, where $g_{m 13}=g_{m 14}=g_{m}$.

$$
G_{m}=\frac{\mathrm{I}_{\mathrm{o}}}{\mathrm{V}_{\mathrm{Y}}}=\frac{g_{m} \cdot r_{0} \cdot g_{\text {mdif }}}{1+g_{m} \cdot r_{0} \cdot g_{\text {mdif }} \cdot R 1} \cong \frac{1}{R 1}
$$

The circuit showed in Figure 4 is modified from Kumngern et al (45). It is uses low-voltage cascade current mirrors and a differential output stage. The current flowing through M13-M14 is copied to the output nodes Z1 and Z2. The phase of the output current at $\mathrm{Z} 2$ node is $180^{\circ}$ phase shifted compared to the $\mathrm{Z} 1$ node. The differential output current $\left(I_{O}\right)$ is calculated by the relationship $V_{Y} / R 1$ (see Figure 4). The circuit linearity $\left(\mathrm{I}_{\mathrm{O}}\right.$ versus $\mathrm{V}_{\mathrm{Y}}$ ) was investigated by DC sweeping of the input voltage signal $\mathrm{V}_{\mathrm{Y}}$ from -0.6 to +0.6 Volts. The frequency response of the output current was measured directly across a $1 \mathrm{k} \Omega$ load. The circuit is supplied by a voltage source of \pm 1.5 Volts.

\section{Results}

It can be seen in Figure 5 that both mirrored modified Howland and current conveyor current sources (CCII) have a linearity error of approximately $0.5 \%$ by exhibiting a constant ratio of $1 \mathrm{mS}$ from -0.5 to +0.5 Volts. On the other hand, the output current of the class-A OTA is not linear over the input voltage range -0.5 to $+0.5 \mathrm{~V}$ by presenting a linearity errors up to $10 \%$, but it is linear between an input voltage from -0.3 to $+0.3 \mathrm{~V}$. 


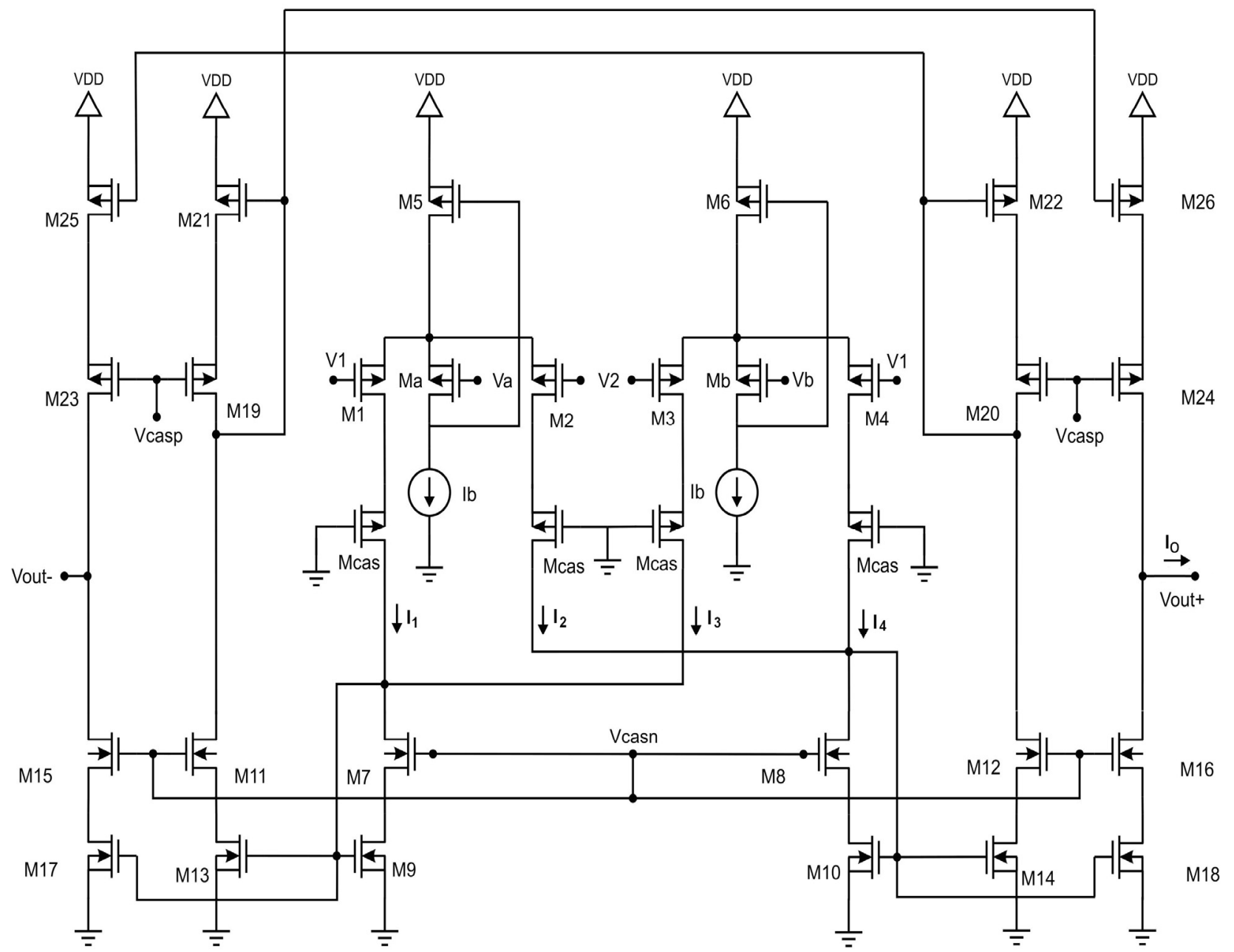

Fig.3: Schematic diagram of the simulated CMOS class-AB operational transconductance amplifier (modified from (40)).

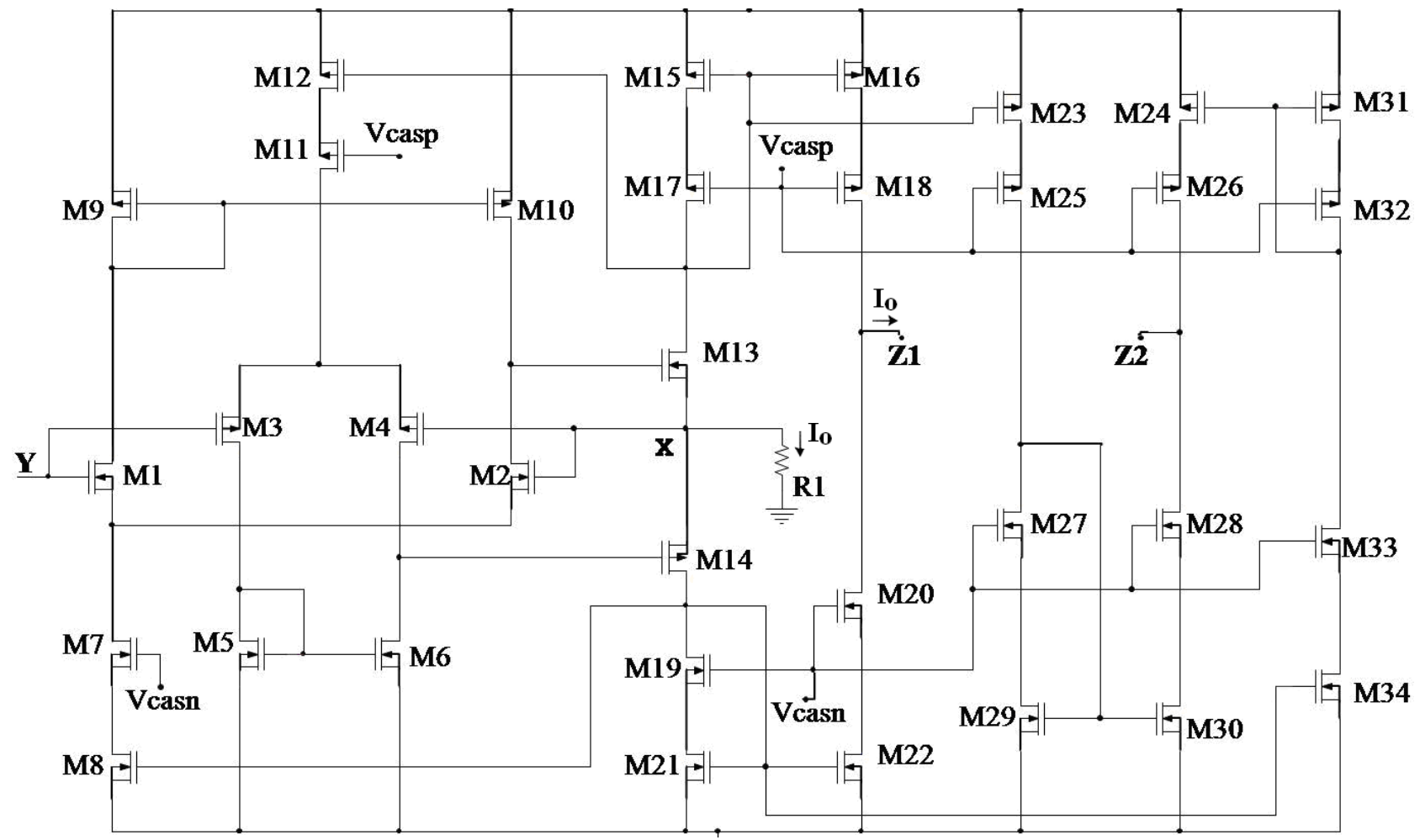

Fig.4: Schematic diagram of the Current Conveyor current source. 
It can be observed in Figure 5 that the class-AB OTA is more linear than the class-A with a maximum linearity error of $6.6 \%$, in the input voltage range -0.5 to $+0.5 \mathrm{~V}$. From Figures 2, 3 and 4 it can be calculated that the power consumption of both class-AB and current conveyor is 1.6 $\mathrm{mW}$ whereas it is $4.6 \mathrm{~mW}$ for the class-A OTA.

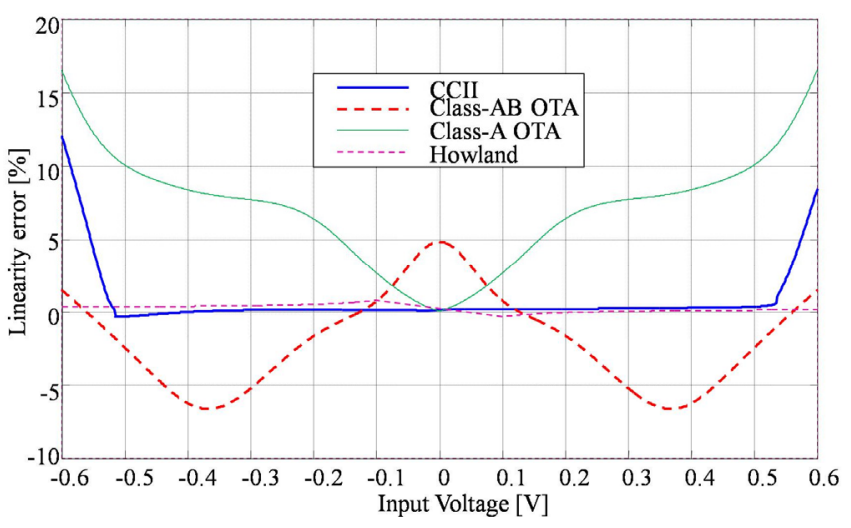

Fig.5: Linearity error response of the current source over the input voltage range -0.6 to $+0.6 \mathrm{~V}$, using a resistive load of $1 \mathrm{k} \Omega$.

In order to investigate the signal distortion generated by the current sources presented in this work, the total Harmonic Distortion (THD) was simulated and the results are show in Figure 6. The THD was investigated at $100 \mathrm{kHz}$ for a load resistor of $1 \mathrm{k} \Omega$. It can be seen that the Howland circuit presents a better THD and it is smaller than $0.5 \%$ over the input voltage from -0.5 to $+0.5 \mathrm{~V}$.

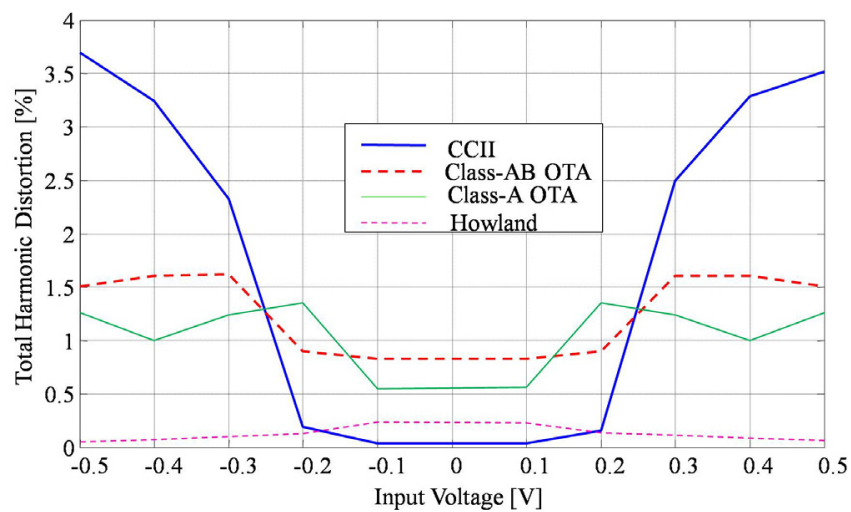

Fig.6: Harmonic distortion as a function of the input voltage.

Figure 7 shows the frequency response of the current sources. It can be seen that the output current of the mirrored modified Howland circuit has a flat bandwidth between approximately $630 \mathrm{~Hz}$ to $5.5 \mathrm{MHz}$ and a current peak of $1.3 \mathrm{mAp}$ at approximately $43.6 \mathrm{MHz}$ (which can be considered as the natural frequency oscillation of the operational amplifiers caused by the second order nonlinearities of the OPA657 circuits) can also be observed. It can also be observed that the class-A OTA can drive 1 $m A_{p p}$ across $1 \mathrm{k} \Omega$ load in a frequency range from $10 \mathrm{~Hz}$ to approximately $20 \mathrm{MHz}$. It can be calculated (Figure 5) that the corner frequency in this type of current source is approximately $234 \mathrm{MHz}$. Figure 5 also shows that the calculated corner frequency in this type of current source is approximately $567 \mathrm{MHz}$ with 37 and $33 \mathrm{MHz}$ for the classAB OTA and current conveyor circuits, respectively.

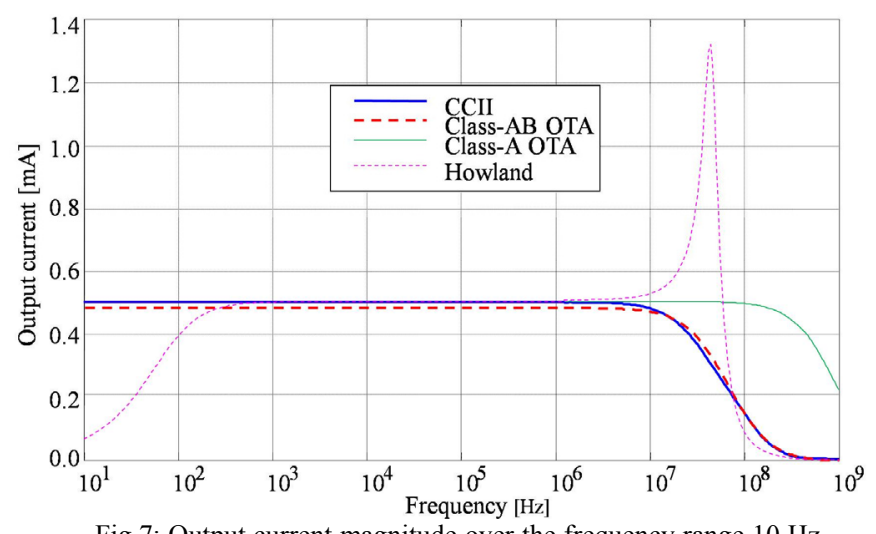

Fig.7: Output current magnitude over the frequency range $10 \mathrm{~Hz}$ to $1 \mathrm{GHz}$.

Figure 8 shows the output impedance frequency responses. It can be seen that the mirrored modified Howland circuit behaves like a bandpass filter, where the maximum output impedance is $1.63 \mathrm{M} \Omega$, the lower corner frequency is 490 $\mathrm{Hz}$ and the upper one is $1.3 \mathrm{MHz}$. It can be observed that both current conveyor and class-AB OTA circuits are identical. Although the maximum output impedance of the class-A OTA is approximately $70.8 \mathrm{M} \Omega$, it decreases to approximately $2.8 \mathrm{M} \Omega$ at $1 \mathrm{MHz}$ and $695.5 \mathrm{k} \Omega$ for the class-A OTA circuit.

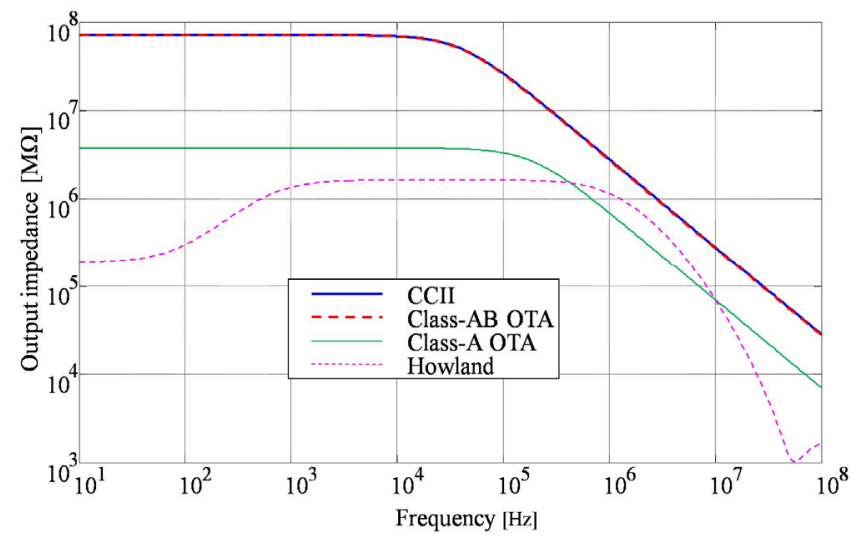

Fig.8: Output impedance over the frequency range $10 \mathrm{~Hz}$ to 100 $\mathrm{MHz}$.

\section{Discussion}

The class-AB OTA and the current conveyor circuit have been shown to have a better performance in the frequency range $10 \mathrm{~Hz}$ to $1 \mathrm{MHz}$ than the others current sources simulated in this work. However, if linearity is required from -0.6 to +0.6 volts the class-AB OTA has showed better results. On the other hand, if low power consumption is required then the current conveyor has the lowest value (1.6 $\mathrm{mW}$ ) compared to the others simulated circuits. Apart from power consumption, one big advantage of using the OTA-based CMOS differential VCCSs is the reduced area occupied on the printed board, which is much smaller than 
the MMHCS circuit based on passive and active components (i.e., resistors and operational amplifiers). The implemented MMHCS circuit with surface mount OPA657 has an area of approximately $20 \mathrm{~mm}^{2}$ whereas the class-AB OTA projected in this paper has a surface area of 0.004 $\mathrm{mm}^{2}$.

The results from the THD showed that the Howland circuit performed better though we must bear in mind that the power supply of the Howland circuit was $\pm 5 \mathrm{~V}$ but only $\pm 1.5 \mathrm{~V}$ for the OTA-based circuits. This may explain some of the differences in performance in terms of linearity and THD.

It is important to emphasize that the performance of both the original and modified Howland current sources depend on the operational amplifier characteristics used in the structure, such as the open-loop gain and the input and output impedance (41). The fact that this type of current source contains both positive and negative feedback loops, resistor mismatching can also degrade the frequency response (14). The most important characteristic of a current source is its output impedance, which is frequency dependent (see Equation 1). If we make $Z_{0}=0, R>>r$ and $A>>2$. Equation 1 can be simplified and then the output impedance of the MMHCS circuit can be given by

$$
Z_{\text {out }}(\omega) \cong r \cdot A(j \omega)=r \cdot \frac{A_{0}}{1+j \omega / \omega_{c 0}}
$$

where $\mathrm{A}_{0}$ is the DC open-loop gain of the op-amp and the $\omega_{\mathrm{c} 0}$ is the open-loop gain cut off frequency. It can be seen that the output impedance of the Howland current source is highly dependent on the open-loop gain of the operational amplifier used. By choosing the OPA657, a maximum differential output impedance of approximately 4.5 $\mathrm{M} \Omega$ is expected. A full critical review of Howland current source circuits is being submitted by the authors to the journal Reviews on Scientific Instruments.

A peak frequency response in the output current of the Howland circuit was observed from the simulations. This may be explained by the second order non-idealities of the operational amplifier, which are taken into account by the SPICE model in the simulations. In practice, this peak does not occur due to the bandwidth constraint of the instrumentation amplifier used in EIS systems. The lower frequencies' response can be improved by increasing the output capacitor, C. of the mirrored modified Howland circuit (see Figure 1). Theoretically, this response can be made down to DC but not in practice since the capacitor works against saturation of the operational amplifier. Optimized modified Howland current sources with an output impedance 100 times greater than the results shown in this work can be found in the literature $(50,51)$, but they suffer from instability problems due to non-idealities of the amplifiers and imbalance of both types of Howland circuits (source and sink circuits), and, therefore, cannot be controlled.

In order to implement the mirrored modified Howland current source it is necessary to match both sides of the circuit, which means that both source and sink sides should have identical output currents (magnitude and phase) $(30,52)$. Bertemes et al. (41) showed that different effects of parasitic capacitances at each side of the mirrored modified Howland current source creates large common mode voltage at the load and degrade the output impedance. They also showed from experimental data that it is possible to balance the MMHCS circuit by trimming the resistors of both non-inverting op-amp inputs (as for example, the resistors " $\mathrm{R}+\mathrm{r}$ " of Figure 1 ).

Although the current source structures projected in this work were only simulated in SPICE, the results are encouraging for the implementation of real life circuits. The mirrored modified Howland current source has already been implemented and the results are shown in BertemesFilho (53). The current conveyor and class-AB OTA current sources proposed in this paper will be designed and prototyped under a semiconductor process. In practice, it has to be emphasized that parasitic capacitances may reduce both the output current and impedance frequency response of the OTA based current sources. However, the frequency bandwidth can be increased by changing the geometry of the transistors. As a result, the cutoff frequency of the current source may be improved in order to prevent parasitic capacitances presented in the experiment.

\section{Conclusion}

This paper simulated the performance of the mirrored modified Howland current source and compared to three types of OTA based CMOS amplifiers. The output current and impedance of the circuits were investigated over the frequency range from $10 \mathrm{~Hz}$ to $1 \mathrm{GHz}$. The class-AB OTA based current source has a better frequency response and lower power consumption than the other current sources. The effects of parasitic capacitances were not simulated, but they can be taken into account when projecting the OTA based current source at a transistor level.

Therefore, even at a simulation level, these results are encouraging the authors to see these circuits created in a semiconductor process. This might be interesting for microimplants and cell impedance measurements.

\section{Acknowledgments}

We thank the State University of Santa Catarina (UDESC) for the financial support.

\section{References}

1. Dean DA, Ramanathan T, Machado D, Sundararajan,R. Electrical Impedance Spectroscopy Study of Biological Tissues. J. Electrostat. 2008;66(3-4):165-77. http://dx.doi.org/10.1016/j.elstat.2007.11.005 
2. Kim BS, Isaacson D, Xia H, Kao TJ et al. A method for analyzing electrical impedance spectroscopy data from breast cancer patients. Physiol Meas. 2007;28(7):S237-46. http://dx.doi.org/10.1088/0967-3334/28/7/S17

3. Keshtkar A, Salehnia Z, Shokouhi, B. Bladder Cancer Detection Using Electrical Impedance Technique (Tabriz Mark 1). Pathology Research International. 2012;2012:1-5. http://dx.doi.org/10.1155/2012/470101

4. Halter RJ, Hartov A, Heaney JA et al. Electrical Impedance Spectroscopy of the Human Prostate. IEEE Transactions on Biomedical Engineering. 2007;54(7):1321-7. http://dx.doi.org/10.1109/TBME.2007.897331

5. Skourou C, Hoopes PJ, Strawbridge RR, Paulsen KD. Feasibility studies of electrical impedance spectroscopy for early tumor detection in rats. Physiological Meas. 2004;25:335-46. http://dx.doi.org/10.1088/0967-3334/25/1/037

6. Skourou C, Rohr A, Hoopes PJ, Paulsen KD. In vivo EIS characterization of tumour tissue properties is dominated by excess extracellular fluid. Phys. Med. Biol. 2007;52:347-63. http://dx.doi.org/10.1088/0031-9155/52/2/003

7. Van Kreel BK. Multi-frequency bioimpedance measurements of children in intensive care. Med. Biol. Eng. Comput. 2001;39:551-7. http://dx.doi.org/10.1007/BF02345145

8. Lingwood BE, Dunster KR, Colditz PB, Ward LC. Noninvasive measurement of cerebral bioimpedance for detection of cerebral edema in the neonatal piglet. Brain Res. 2002;945:97-105. http://dx.doi.org/10.1016/S0006-8993(02)02744-0

9. Seoane F, Lindecrantz K, Olsson T et al. Spectroscopy study of the dynamics of the transencephalic electrical impedance in the perinatal brain during hypoxia. Physiol. Meas. 2005;26: 849-63. http://dx.doi.org/10.1088/0967-3334/26/5/021

10. Moissl UM, Wabel MP, Chamney PW et al. Body fluid volume determination via body composition spectroscopy in health and disease. Physiological Measurement. 2006;27(9):921-33. http://dx.doi.org/10.1088/0967-3334/27/9/012

11. Wang ZM, Deurenberg P, Guo SS et al. Six-compartment body composition model: Inter-method comparisons of total body fat measurement. International Journal of Obesity. 1998;22:329-37. http://dx.doi.org/10.1038/sj.ijo.0800590

12. Bertemes-Filho, P, Negri, L, Paterno, AS. Detection of bovine milk adulterants using bioimpedance measurements and artificial neural network. In: 5th European Conference of the International Federation for Medical and Biological Engineering. Budapest: 2011. p. 1275-8. http://dx.doi.org/10.1007/978-3-642-23508-5_330

13. Paterno AS, Bertemes-Filho, P, Negri, LH. Efficient computational techniques in bioimpedance spectroscopy. In: Applied Biological Engineering - Principles and Practice. Rijeka: InTech - Open Access Publisher. 2012:1-26. http://dx.doi.org/10.5772/36307

14. Bertemes-Filho P. Tissue Characterisation using an Impedance Spectroscopy Probe. $\mathrm{PhD}$ thesis. University of Sheffield. 2002. 96 p.
15. Grimnes S, Martinsen OG. Bioimpedance and Bioelectricity Basics. Academic Press. 2000. 360 p.

16. Yúfera A, Rueda A. Design of A CMOS Closed-Loop System Useful for Bio-Impedance Measurements . In: 16th IEEE International Conference on Electronics, Circuits and Systems. Tunisia: 2009. p. 948-51.

17. Ferreira J, Seoane F, Ansede A, Bragos R. AD5933-based spectrometer for electrical bioimpedance applications. Journal of Physics: Conference Series. 2010; 224(1):1-4.

18. Analog Devices AD5933 Product web site. Accessed on 2010-01-15. Available from:

http://www.analog.com/en/AD5933/productsearch.html.

19. Ruha A, Kostamovaara J, Saynajakangas S. A micropower analog-digital heart rate detector chip. Analog Integrated Circuits and Signal Processing. 1994; 5:147-68. http://dx.doi.org/10.1007/BF01272649

20. Novo A, Gerosa A, Neviani A. A submicrometer CMOS programamable charge pump for implantable pacemarker. Analog Integrated Circuits and Signal Procesing. 2001;21:211-7.

21. Yúfera A, Leger G, Rodríguez-Villegas EO et al. An integrated circuit for tissue impedance measure. In: Proc. 2nd Ann. Int. IEEE EMBS. Madison: 2002. p. 88-93.

22. Aberg P, Nicander I, Ollmar S. Minimally invasive electrical impedance spectroscopy of skin exemplified by skin cancer assessments. 7. In: IEEE Proc. of the EMBS Annual Int. Conf. Cancun: 2003. p. 3211-14.

23. Emtestam L, Nicander I, Strenstrom M, Ollmar S. Electrical impedance of nodular basal cell carcinoma: A pilot study. Dermatology. 1998;197:313-6. http://dx.doi.org/10.1159/000018023

24. Brown BH, Tidy J, Boston K, et al. Tetrapolar measurement of cervical tissue structure using impedance spectroscopy. In: 20th Annual Int. Conf. on Biomed. Eng. 1998. IEEE Proc. vol 4. p. 2886-9.

25. González-Correa CA, Brown BH, Smallwood RH, et al. Virtual Biopsies in Barrett's Esophagus using an Impedance Probe. Annals New York Academy of Scienc. 1999;873:31321. http://dx.doi.org/10.1111/j.1749-6632.1999.tb09479.x

26. Aberg P, Nicander I, Hansson J, Geladi P, Holmgren U, Ollmar S . Skin Cancer Identification Using Multifrequency Electrical Impedance - A Potential Screening Tool . IEEE Transactions on Biomedical Engineering. 2004;51(12):2097102. http://dx.doi.org/10.1109/TBME.2004.836523

27. Seoane F, Macías R, Bragós R, Lindecrantz K. Simple voltage-controlled current source for wideband electrical bioimpedance spectroscopy: circuit dependences and limitations. Measurement Science and Technology. 2011;22(11):1-11. http://dx.doi.org/10.1088/0957-0233/22/11/115801

28. Lu L, Brown BH. The electronic and electronic interface in an EIT spectroscopy system. Inn. Tech. Biol. Med. 1994;15:97-103.

29. Bertemes-Filho P, Brown BH, Wilson AJ. A comparison of modified Howland circuits as current generators with current mirror type circuits. Physiol. Meas. 2000;20:1-6. http://dx.doi.org/10.1088/0967-3334/21/1/301 
30. Bertemes Filho P, Lima RG, Amato MBP et al. Performance of an Adaptative Multiplexed Current Source used in Electrical Impedance Tomography. In: XX Brazilian Congress Biomed. Eng. 2006; p. 1167-70.

31. Seoane F, Bragós R, Lindecranz K. Current source for multifrequency broadband electrical bioimpedance spectroscopy systems: a novel approach. In: IEEE Proc. of the EMBS Annual Int. Conf. New York: 2006. p. 5121-5.

32. Yufera A, Rueda A, Munoz J M et al. A tissue impedance measurement chip for myocardial ischemia detection. IEEE Transactions Circuits Syst. 2005;52(12).

33. Tsunami D, McNames J, Colbert A et al. Variable Frequency Bioimpedance Instrumentation. In: Annual Int. Conf. of the IEEE EMBS. San Francisco: 2004. p. 1-5.

34. Hong, H, Rahal, M, Demosthenous, A et al (2007), Floating Voltage-Controlled Current Sources for Electrical Impedance Tomography, 18th European Conference on Circuit Theory and Design, 2007, pp 208-211. http://dx.doi.org/10.1109/ECCTD.2007.4529573

35. Uranga A, Sacristán J, Osés T et al. Electrode-tissue Impedance Measurement CMOS ASIC for Funtional Electrical Stimultion Neuroprostheses. IEEE Transactions on Inst.\&Meas. 2007;56(5):2043-50.

36. Boone KG, Holder DS. Current approaches to analogue instrumentation design in electrical impedance tomography. Physiol. Meas. 1996;17:229-47. http://dx.doi.org/10.1088/0967-3334/17/4/001

37. Raghed AO, Geddes LA, Bourland JD et al. Tetrapolar electrode system for measuring physiological events by impedance. Med. Biol. Eng. Comput. 1992;30:115-7. http://dx.doi.org/10.1007/BF02446203

38. Jivet I, Dragoi B. On-electrode autonomous current generator for multi-frequency EIT. Physiol. Meas. 2008;29:S193-201. http://dx.doi.org/10.1088/0967-3334/29/6/S17

39. Casas O, Rosell J et al. A parallel broadband real-time system for electrical impedance tomography. Physiol. Meas. 1996; 17:A1-6. http://dx.doi.org/10.1088/0967-3334/17/4A/002

40. Seoane F, Bragos R, Lindecrantz K, Riu PJ. Current Source Design for Electrical Bioimpedance Spectroscopy. In: Encyclopedia of Healthcare Information Systems. 2008. p. 359-67.

41. Seoane F, Bragós R, Lindercrantz K, Riu PJ. Current Source Design for Electrical Bioimpedance Spectroscopy. In: Encyclopedia of Healthcare information Systems. New York: 2008. p. 359-66.

42. Vincence VC, Galup-Montoro C, Schneider MC. A High Swing MOS Cascode Bias Circuit. IEEE Trans. Circuits and Systems. 2000;47(11):1325-8. http://dx.doi.org/10.1109/82.885143

43. Carvajal RG, Ramírez-Angulo J, López-Martín A et al. The Flipped Voltage Follower: A Useful Cell for Low-Voltage Low-Power Circuit Design. IEEE Transactions on Circuits and Systems. 2005;52(7):1276-91. http://dx.doi.org/10.1109/TCSI.2005.851387

44. Salem SB, Fakhfakh A, Loulou M, Loumeau P, Masmoudi N. A 2.5V 0.35 $\mu \mathrm{m}$ CMOS Current Conveyor and High Frequency High-Q Band-Pass Filter. In: Proceedings of the 16th International Conference on Microelectronics. Tunis: 2004. p. 328-33. http://dx.doi.org/10.1109/ICM.2004.1434578

45. Kumngern M, Moungnoul P, Junnapiya S, Dejhan K. Current-mode universal filter using translinear current conveyors. In: Proceedings of the 5th International Conference on Electrical Engineering/Electronics, Computer, Telecommunications and Information Technology. Krabi: 2008. p. 717-20.

46. Knobnob B, Kumngern M, Dejhan K. Current-mode quadrature oscillator using translinear current conveyors. In: Proceedings of the 2008 International Symposium on Communications and Information Technologies. Vientiane: 2008. p. 196-9. http://dx.doi.org/10.1109/ISCIT.2008.4700181

47. Arslan E, Morgul A. Wideband self-biased CMOS CCII. In: Proceedings of the $2008 \mathrm{PhD}$ research in microelectronics and electronics. Istanbul: 2008. p. 217-20. http://dx.doi.org/10.1109/RME.2008.4595764

48. Ibrahim MA, Kuntman H, Cicekoglu O. A very highfrequency CMOS self-biasing complementary folded cascade differential difference current conveyor with application examples. In: Proceedings of the 45th Midwest Symposium on Circuits and Systems, Oklahoma: 2002. p. 279-82.

49. Ferri G, Guerrini NC. Low-voltage, low-power CMOS current conveyors. Dordrecht: Kluwer Academic Publishers, 2003.

50. Ross AS, Saulnier GJ, Newell JC, Isaacson D. Current source design for electrical impedance tomography. Physiological Measurement. 2003; 24(2):509-16. http://dx.doi.org/10.1088/0967-3334/24/2/361

51. Bertemes-Filho P, Lima RG, Tanaka H. A Current Source using a Negative Impedance Converter (NIC) for Electrical Impedance Tomography (EIT). In: Proceedings of the 17th International Congress on Mechanical Engineering. São Paulo: 2003. p. 83-7.

52. Bertemes-Filho P, Paterno AS, Pereira, RM. Multichannel Bipolar Current Source Used in Electrical Impedance Spectroscopy: Preliminary Results. In: World Congress on Medical Physics and Biomedical Engineering. Munich: 2009. p. 657-60.

53. Bertemes-Filho P, Vincence VC, Zanatta IX. A Comparison of Modified CMOS Transconductance Amplifiers with Howland Circuit for Low Power Electrical Bioimpedance Instrumentation. In: 5th European Conference of the International Federation for Medical and Biological. Budapest: 2011. p. 1-4. http://dx.doi.org/10.1007/978-3-642-23508-5_53 